Type of the Paper (Article, Review, Communication, etc.)

\title{
Measuring river surface velocity with Doppler radar and Parti- cle Image Velocimetry (PIV) using Unmanned Aerial Systems (UASs)
}

\author{
Filippo Bandini ${ }^{1, *}$, Monica Coppo Frias ${ }^{1}$, Jun Liu ${ }^{1}$, Kasparas Simkus ${ }^{1}$, Sofia Karagkiolidou ${ }^{1}$, Peter Bauer-Gottwein ${ }^{1}$
}

1 Department of Environmental Engineering, Technical University of Denmark, 2800 Kgs. Lyngby, Denmark; fban@env.dtu.dk (F.B.), mcfr@env.dtu.dk (M.C.F.), juli@env.dtu.dk (J.L.),pbau@env.dtu.dk (P.B.)

* Correspondence: fban@env.dtu.dk

\begin{abstract}
Surface velocity is traditionally measured with in-situ techniques such as velocity probes (in shallow rivers) or Acoustic Doppler Current Profilers (in deeper water). In the last years, researchers have developed remote sensing techniques, both optical (e.g. image-based velocimetry techniques) and microwave (e.g. Doppler radar). These techniques can be deployed from Unmanned Aerial Systems (UAS), which ensure fast and low-cost surveys also in remote locations. We compare the results obtained with a UAS-borne Doppler radar and UAS-borne Particle Image Velocimetry (PIV) in different rivers, which presented different hydraulic conditions (width, slope, surface roughness and sediment material). The Doppler radar was a commercial $24 \mathrm{GHz}$ instrument, developed for static deployment, adapted for UAS integration. PIV was applied with natural seeding (e.g. foam, debris) when possible, or with artificial seeding (woodchips) in the stream where the density of natural particles was insufficient. PIV reconstructed the velocity profile with high accuracy typically in the order of a few $\mathrm{cm} / \mathrm{s}$ in all investigated rivers, whilst UAS-borne radar was only successful in locations with high water roughness. However, UAS integration of Doppler radar is complex because of vibrations, large instrument sampling footprint, large required sampling time and difficult-to-interpret quality indicators.
\end{abstract}

Keywords: UAS; drone; Doppler radar; PIV; river; velocity.

\section{Introduction}

Measurements of surface velocity in rivers are essential to evaluate sediment deposition and erosion processes [1,2] especially during high flow periods [3], study fish migration [4-6] and estimate discharge [7-12]. In shallow rivers, where the operator can wade through, velocity is generally measured with a velocity probe (propeller-based or electromagnetic instruments), whilst Acoustic Doppler Current Profiler (ADCP) is typically used in deeper rivers. Researchers have also experimented with contactless techniques for measuring surface velocity, such as optical and radar methods. Among the optical methods, Particle Image Velocity (PIV) and Particle Tracking velocimetry (PTV), are the most widely used methods [13-17], although recently, new algorithms have been developed and cross-compared (e.g. [18,19]). The PTV technique is based on the identification and tracking of individual particles [20-23]; whilst PIV recognizes and tracks patterns (which can be a group of particles in an interrogation area on the water surface) [24-27]. Many studies (e.g. [7,15,28-30]) demonstrated the application of PIV or PTV to videos acquired from Unmanned Aerial Systems (UASs) for surface velocity estimation.

Radar velocimetry methods are typically based on the Doppler effect, i.e. the change in frequency of a signal reflected by a moving target. In particular, when microwaves are incident on rough water surfaces at intermediate incidence angles, they are scattered back 
to the receiver by short surface waves [31]. This phenomenon is known as composite surface scattering in which Bragg-resonant scattering is predominant. Bragg scattering is mainly caused by short surface waves (length is defined by the Bragg resonance condition, typically a few centimeters) [32-35]. The short waves causing Bragg-resonant scattering are generally caused by wind, or indirectly by longer waves, by the turbulence of the water, or by rainfall $[36,37]$.

Plant et al. [31] developed and tested a continuous wave Doppler microwave system (24 GHz), a pulsed Doppler radar $(10 \mathrm{GHz})$, and an airborne real aperture coherent radar (9.36 GHz). Measurements of river surface velocity from bridges, cableways, and river banks in rivers (with maximum velocity $>2 \mathrm{~m} / \mathrm{s}$ ) were shown to be accurate to within ca. $10 \mathrm{~cm} / \mathrm{s}$ when compared with in situ measurements for both continuous wave and pulse radar; however, the authors reported that water roughness is sometimes insufficient for providing sufficient signal along the entire cross-section (XS) of natural streams. Furthermore, Plant et al. [31] (results from the same test are also reported in [38]) also tested helicopter-borne and airplane-borne deployment of a real aperture coherent radar (a slightly modified version of the pulse radar). In this case, the transmitting and receiving antennas were separated so that signals from shorter ranges could be received without interference from ringing of the transmitted pulse. The helicopter was flown perpendicularly to the flow with a set of transmitting/receiving antennas mounted on each side of the helicopter to be able to cancel out the velocity component caused by the helicopter-generated downwash. The helicopter surveys showed that velocity can be recorded and compared with ground-truth if the helicopter is flown only a few meters above the water surface and if the propeller-generated downwash is used to increase water roughness, whilst the airplane test was less successful and showed that velocities could be detected infrequently and ground truth comparison could not be performed. Furthermore, both tests showed that an appreciable component of the water velocity should be in the antenna look direction in order to obtain reliable results.

Plant et al. [31] also examined the possibility to detect surface velocity with a spaceborne or air-borne along-track interferometric synthetic aperture radar (InSAR) and its limitation in terms of spatial resolution, minimum river width, water roughness and return power. Recently, Biondi at al. [39] have demonstrated the possibility to measure surface velocity with UAVSAR, an L-band SAR developed by NASA (characteristics are reported in [40]), showing that high velocity measurements correlated well with the river portions where high velocities are expected from river morphology.

However, although handheld and stationary (e.g. bridge-mounted) radars proved able to monitor surface velocity [41-44] (but were shown to be less reliable in low flow conditions [45]), deployment of radar on UAS for measuring river surface velocity is a new and challenging development. Alimenti et al. [46] developed a prototype of a lowcost continuous wave $(24 \mathrm{GHz})$ Doppler radar sensor that was deployed stationary from a bridge in two sites along the Tiber River (Italy) and provided promising results when compared to another reference radar and prior information of surface velocity distributions. In their outlook on future work, the authors discussed UAS deployment of this instrument. To date, there is only one study reporting actual UAS-deployment of a Doppler radar sensor [47], in which Fulton et al. tested a continuous wave $24 \mathrm{GHz}$ Doppler radar (developed by the USGS and Sommer Messtechnik) in five flights over four different rivers in the USA. UAS-borne observations were compared with another reference handheld radar and an acoustic Doppler velocimeter: differences were typically of a few $\mathrm{cm} / \mathrm{s}$ when comparing the velocity value retrieved at the location of maximum velocity; however, comparisons of the horizontal velocity profile across the XS are not reported in the paper. Furthermore, the authors reported that the radar was not working in sites with surface velocities less than $0.15 \mathrm{~m} / \mathrm{s}$ and that more research is needed to understand the effects of (i) the propeller-generated downwash on water velocity and roughness, (ii) sampling duration, (iii) quality of the scattered signal, (iv) wind, in order to improve filtering methods and to evaluate performance in different hydrological conditions. 
In this paper, we report the application of a commercial Doppler radar for measuring water surface velocity in rivers with different hydraulic conditions (velocity, water roughness, slope, width). A commercial Doppler radar was readapted for UAS-borne use, to ensure a faster survey time and was flown across the entire XS: indeed, a profile of surface velocity across the XS, instead of only measurements in one single location (e.g. where maximum velocity occurs or in the stream middle), is expected to provide better information about river flow. The Doppler radar was compared with UAS-borne PIV and with ground-truth (electromagnetic velocity probe measurements). PIV was chosen for this research, because, whilst PTV may provide better results in some conditions (e.g. non-uniform or poor seeding density, unsteady flow), PTV would also require particles of well-defined shape and with a particle size smaller than frame-to-frame displacement [17]. Thus PIV was considered more suitable because natural seeding (e.g. foam or natural particles on the water surface) was used in most cases.

\section{Materials and Methods}

\subsection{UAS platform and payload}

In this research, the deployed drone was a DJI Matrice 600 PRO (DJI, China). We developed a UAS payload consisting of i) the GNSS (Global Navigation Satellite System) NovAtel OEM7700 (NovAtel, Canada) receiver connected to Antcom (3G0XX16A4-XT-14-Cert) multiband antenna ii) the IWR1443BOOST radar from Texas Instrument (USA) iii) the RGB video-camera GoPro Hero 5 (GoPro, USA) iv) the Doppler radar OTT SVR (OTT HydroMet, Germany) and v) the single-board computer BeagleBone Black (BeagleBoard.org), which logged and synchronized observations of the different sensors. Both the RGB camera and the IWR1443Boost were mounted on the gimbal Gremsy T1 (Gremsy Co., Ltd, Vietnam).

In this research, the IWR1443BOOST is used only to measure the range to water surface [48] and thus ensure that the UAS is kept at a precise elevation above the water surface.

The video-camera GoPro Hero 5 is used to retrieve a video sequence of the water flow in 1080p HD at $60 \mathrm{~Hz}$.

The OTT SVR100 (from here on abbreviated as SVR (Surface Velocity Radar)) is a commercial $24 \mathrm{GHz}$ (K-band) Surface Velocity Radar emitting radar pulses and detecting Doppler shift of the reflected pulses for water surface velocity estimation. It is specifically developed to be used in static deployment (i.e. typically mounted on bridges). The SVR uses complex Kalman filters with physical modelling of the water flow to give stable measurements even in turbulent conditions.

The radar beam, with a measuring angle of $12^{\circ}$ (Azimuth) and $24^{\circ}$ (Elevation), covers an elliptical area on the water surface; however, the radar outputs only the averaged surface velocity in the illuminated area. The SVR should be mounted with a tilt between $30^{\circ}$ and $60^{\circ}$ with respect to the horizontal, with $30^{\circ}$ resulting in the largest footprint but typically the strongest return signal. The manufacturer datasheet states that the SVR can measure water velocity (range between 0.08 and $15 \mathrm{~m} / \mathrm{s}$ ) with a resolution of $0.1 \mathrm{~mm} / \mathrm{s}$ and accuracy of $\pm 2 \%$ of the measured value. It can measure velocity from a distance between 0.5 to $20-25 \mathrm{~m}$ above the water surface. A minimum surface roughness is required for sufficient signal-to-noise ratio and the manufacturer suggests at least $1 \mathrm{~mm}$ minimum wave height.

The SVR is sold with a large case and heavy mounting brackets (which are used to set different mounting angles). The system was readapted to make it suitable for UAS deployment, specifically: i) the case and mounting brackets were removed and substituted with a lightweight case, ii) a new mounting method (based on holes with different positions) was designed to allow the user to set 3 different sensor tilt angles, iii) vibration 
damping was provided to decrease the effect of high-frequency vibrations caused by the drone. The UAS-adapted version is shown in Figure 1.

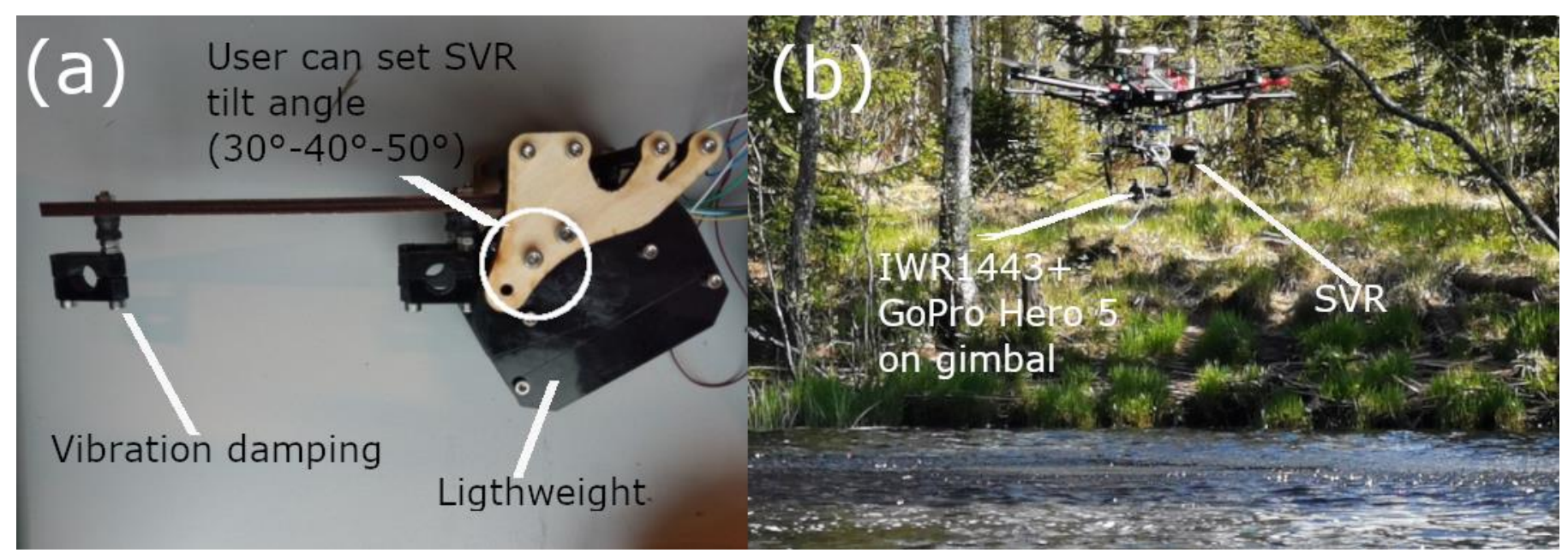

Figure 1. Pictures of UAS payload. (a) SVR adaption for being used as drone payload (b) UAS flight with SVR Doppler radar, IWR1433boost radar and GoPro Hero 5 RGB camera.

\subsubsection{SVR outputs}

The SVR has different outputs (via the RS232 protocol): flow velocity, flow direction, mounting angle, vibration index, Signal-to-Noise Ratio (SNR), programmable gain amplifier (PGA) and another quality indicator of the detected level of the signal reflected from the water surface.

The SVR takes approximately 20 internal measurements per second; however, those high frequency measurements are not available to the user and are internally processed in the built-in processor of the SVR board. Indeed, SVR instantaneous measurements can be very scattered depending on factors such as roughness, wind influence and water turbulence. For this reason, the built-in processor of the SVR board applies filters to smooth out velocity measurements; specifically, two filters are available: infinite impulse response and moving average. The velocity value that is output via the RS232 protocol ca. once a second is internally computed after applying one of these two filters to the instantaneous velocity measurements. We chose to apply the moving average filter with a filter length of 50 measurements, following the recommendations from the manufacturer. The flow direction can assume two values: 1 for approaching (when the sensor points upstream),1 for receding. The SVR tilt angle is measured with an inclinometer in degrees. The vibration index provides qualitative information and varies in a range from 0 (no vibrations, i.e. ideal measurement) to 3 (very strong vibrations, i.e. data unacceptable). SNR is an indication of the quality of the received signal (and is measured by superimposing the received signal to an interfering signal); it is defined as the logarithm of the ratio of the average power of the desired signal and the average noise power of the interfering signal. When larger energy is reflected from the water surface (typically for higher water surface roughness values), the overall signal strength is higher and, assuming constant noise, SNR should increase: SNR should be $>6$ debibel-milliWatts $(\mathrm{dBm})$ for excellent signal quality. To improve SNR internally, the radar uses low-noise PGA. If the strength of the reflected signal is low, the radar will increase the gain level on PGA. The automatic gain control of the SVR automatically adjusts the PGA gain level. PGA is also an output of the SVR and, according to the manufacturer, should fall between 5 and 100 for ideal measurements: a PGA lower than 5 indicates very strong signal but may also indicate receiver saturation and thus reduced accuracy. The output SNR is available only in the latest firmware version, whilst the former firmware provided another indicator instead, the detected level of signal reflection, that was often hard to interpret in practice. 


\subsubsection{Ground-truth velocity observations}

In most cases, ground-truth observations were retrieved with the electromagnetic flowmeter OTT MF pro (OTT HydroMet, Germany), from here on abbreviated as MFpro. The probe requires to be fully submerged, so observations could not be acquired exactly at the surface level but a few centimetres below the water surface [49] [7].

In one $\mathrm{XS}$, ground-truth observations were retrieved with the ADCP Teledyne StreamPro (Teledyne RD Instruments, USA) instead of the MFpro. The ADCP has a blind zone at the surface level: surface velocity was thus assumed equal to the velocity measured at the depth closest to the surface $(0.2 \mathrm{~m}$ below).

\subsection{Study areas}

Careful site selection is important in order to evaluate the performance of the UAVborne SVR. Indeed, for retrieving at least a few velocity points across the river, the minimum surface roughness requirement and the footprint of the sensor required rivers with visible surface waves and a width of at least 10-15 meters. Danish streams are representative of lowland streams at medium-high latitudes: they are characterized by mild slopes (in the order of a few $\mathrm{cm}$ or tens of $\mathrm{cm}$ per $\mathrm{km}$ ) with clay or silt as riverbed material and dense aquatic vegetation. For these reasons, stream velocity is typically rather low and water roughness is mainly caused by wind. In previous surveys (not reported in this paper), XSs in other Danish streams (Grindsted $\AA$, Vejle $\AA$ ) were surveyed with SVR but the surface roughness was insufficient for reliable measurements. Thus surveys in Denmark were conducted in Guden $\AA$, which is the largest river in Denmark in terms of discharge and river width. Furthermore, surveys were conducted in Swedish streams, which are typically larger, steeper and with stony or gravelly riverbeds, thus typically have higher water surface roughness than Danish rivers. In Sweden, three different XSs in three rivers (Krokån, Kilan and Ätran) were surveyed. 
Table 1 shows the site names, coordinates and the conducted measurements of each survey. 
Table 1, overview of the surveyed sites. Two XSs were surveyed in one river (Guden $\AA$ ) in Den-

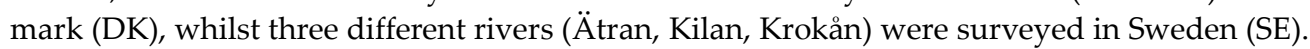
Different surveys were conducted with different instruments: UAS-borne OTT SVR100 ("UASSVR"), UAS-borne Particle Image Velocimetry ("UAS-PIV”), Static OTT SVR100 from bridge ("Static-SVR") and, as ground-truth, either the electromagnetic probe OTT MFpro ("MFpro") or the ADCP Teledyne StreamPro ("ADCP")

\begin{tabular}{|c|c|c|c|c|c|}
\hline \multirow{2}{*}{ Site name } & \multirow{2}{*}{$\begin{array}{l}\text { Loca- } \\
\text { tion }\end{array}$} & \multicolumn{2}{|c|}{$\begin{array}{l}\text { Coordinates of markers } \\
\text { Lat, Long }\left(\left(^{\circ}\right)\right.\end{array}$} & \multirow{2}{*}{$\begin{array}{l}\text { Survey date } \\
\text { (dd/mm/yy) }\end{array}$} & \multirow{2}{*}{ Conducted surveys } \\
\hline & & $\begin{array}{l}\text { Left } \\
\text { Stream- } \\
\text { bank }\end{array}$ & $\begin{array}{l}\text { Right stream- } \\
\text { bank }\end{array}$ & & \\
\hline Guden_Svostrupvej & DK & $\begin{array}{l}56.2233 \\
9.66901\end{array}$ & $\begin{array}{l}56.22319 \\
9.669384\end{array}$ & $14 / 02 / 2020$ & $\begin{array}{c}\text { UAS-SVR } \\
\text { UAS-PIV } \\
\text { ADCP }\end{array}$ \\
\hline $\begin{array}{l}\text { Guden_Gam- } \\
\text { leSkibelundvej }\end{array}$ & DK & $\begin{array}{l}56.36587 \\
9.634325\end{array}$ & $\begin{array}{c}56.36568 \\
9.63458\end{array}$ & $23 / 06 / 2020$ & $\begin{array}{c}\text { Static-SVR } \\
\text { UAS-SVR } \\
\text { UAS-PIV } \\
\text { Mfpro }\end{array}$ \\
\hline Ätran & SE & $\begin{array}{c}57.275260 \\
12.99929\end{array}$ & $\begin{array}{l}57.27526 \\
12.99856\end{array}$ & $28 / 05 / 2021$ & $\begin{array}{l}\text { UAS-SVR } \\
\text { UAS-PIV }\end{array}$ \\
\hline Kilan & SE & $\begin{array}{c}57.04974 \\
13.1166\end{array}$ & $\begin{array}{l}57.04985 \\
13.11617\end{array}$ & 29/05/2021 & $\begin{array}{c}\text { UAS-SVR } \\
\text { UAS-PIV } \\
\text { Mfpro }\end{array}$ \\
\hline Krokån & SE & $\begin{array}{l}56.54607 \\
13.32273\end{array}$ & $\begin{array}{l}56.54636 \\
13.32207\end{array}$ & 30/05/2021 & $\begin{array}{c}\text { UAS-SVR } \\
\text { UAS-PIV } \\
\text { Mfpro }\end{array}$ \\
\hline
\end{tabular}

\subsection{Data acquisition and processing}

\subsubsection{GNSS processing}

GNSS data were post-processed with the software RTKLIB Demo5 b34b from http://www.rtklib.com/ [50] to obtain a Post-Processed Kinematic (PPK) solution (typically resulting in UAS horizontal position accuracy of a few centimeters). As basestation, a NovAtel Flexpack6 receiver with a NovAtel GPS-703-GGG pinwheel triple frequency (GPS and GLONASS) antenna was used.

\subsubsection{PIV}

The UAS platform was flown to the centre of the stream to retrieve a video of the water flow. The post-processing workflow is similar to the one reported in [7]; in summary:

1. A sequence of frames of ca. 5-10 seconds was extracted from the video.

2. A MATLAB script was used to stabilize the video by using natural stable features on the ground (e.g. rocks, land);

3. Lens distortion was corrected using the calibration-derived camera intrinsic parameters; 
4. A masking method was applied to the video frames to convert the RGB frames into binary images, in which white is assigned to the seeding particles (natural or artificial), while black is assigned to the surroundings (e.g. water surface);

5. The surface velocity field was estimated with the image cross-correlation techniques implemented in the open-access software PIVlab for MATLAB [51]. A region of interest (ROI) was drawn where surface velocity along the XS had to be computed: the width of the ROI was equal to the river width and its length was ca. 4-5 meters along the river course. In the PIV analysis, four different interrogation areas of size 256, 128, 64, and 32 pixels were chosen. After the PIV analysis, standard deviations (temporal standard deviation across video sequence) of the velocity vectors were analyzed: only a few frames showing clear outliers in velocity vectors (typically due to UAS vibrations or sudden movements) were discarded. A velocity field was extracted by computing the mean velocity vectors over the non-discarded frames.

6. The velocity in pixel units was then converted into metric unit. To this end, the coordinates of two markers (one pole on each streambank) were used to estimate the ratio between distance in pixel and distance in meters. The coordinates of two markers were found by identifying the position of the two markers in a previously acquired UAS-borne orthophoto.

Thus, compared to the previous methodology reported in [7], we applied a masking method (simply based on identifying a range of values, for the image RGB values, that can be used to separate seeding particles from the background). An example of the black and white mask is shown in Figure 2. Figure 2 shows that the applied mask can separate between seeding and surrounding water, with a few misclassified areas (typically areas with sunglint, e.g. in the area under the bridge shown in the bottom panels of Figure 2). For distinguishing between seeding and surroundings, the applied mask method proved to be better than the standard image pre-processing algorithms used by PIVlab, such as histogram equalization, intensity high-pass filter, and intensity capping.

Only in one case (Gudenå), the water surface did not contain a sufficient number of natural particles for successful PIV analysis, thus artificial seeding (woodchips) was thrown into the water by two operators standing on an upstream bridge. In all surveyed XSs in Sweden, the streams showed a sufficient number of natural particles on the water surface (small floating wood particles, debris and especially foam generated by organic decomposition occurring in the nearby forests) and thus no artificial seeding was added.

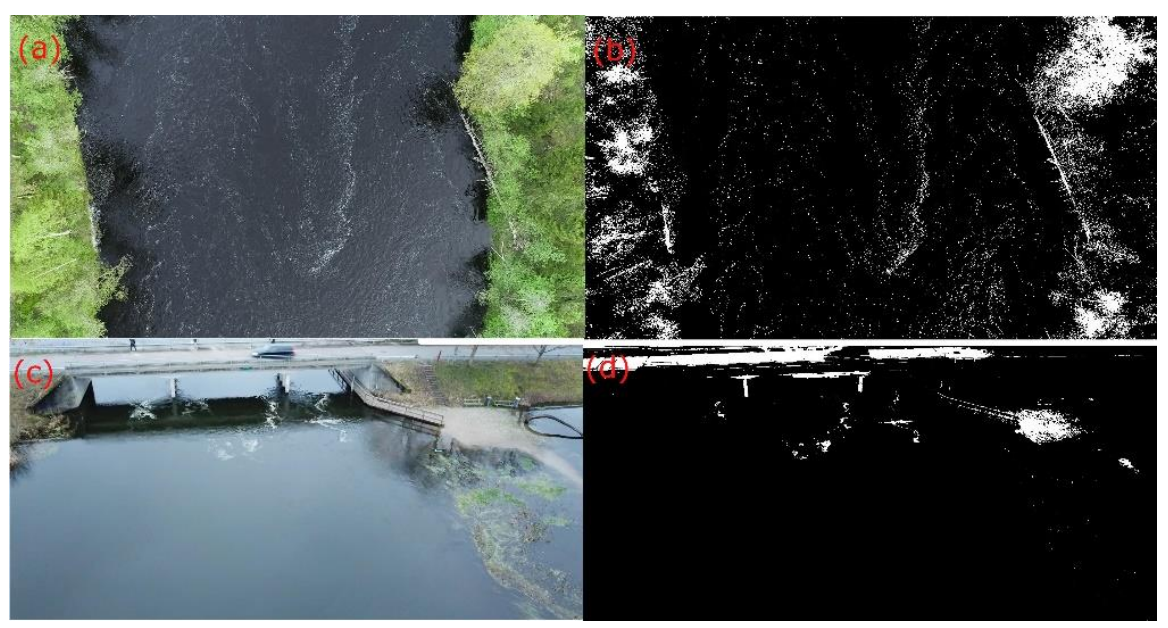

Figure 2. A mask was applied to the RGB video frames (left panel) to obtain a binary image (right panels): white color is assigned to seeding, whilst a black color is assigned to water surface (with a few outlier). (a) and (b) are in case of natural seeding (mainly foam), whilst (c) and (d) are in case of artificial seeding (woodchips). 


\subsubsection{SVR}

At a short temporal scale, river waves can be dominated by eddies and secondary currents. Thus if the sampling time of a Doppler radar was inadequate and eddies were large, the radar would measure the eddy-dominated velocities rather than the surface scatterers that are located on the surface of larger scale waves, which represent the river flow primary velocity [47]. Thus the SVR instrument has internal filters to smooth velocity measurements and cancel the effect of local eddies. Because of these internal filters, the SVR requires a long time (at least 30 seconds) during which the sensor is stable to smooth velocity readings and accurately measure surface velocity. Thus, the SVR was flown across the stream from the left to the right streambank, but shifted with respect to the XS line because the centre of the footprint of the SVR is not directly below the SVR (as a result of the SVR tilt). During the planned flight, the UAS was stopped at regular intervals (ca. every 1-2 meters) to retrieve observations for ca. 1 minute. The flight speed between those hovering intervals was as low as possible (ca. $0.5 \mathrm{~m} / \mathrm{s}$ ) and the flight direction was planned to keep the UAS nose pointing perpendicular to the flow; however, the uncertainty in flow direction and the inaccuracy in drone heading can generate an error of a few degrees in UAS orientation with respect to flow direction.

SVR orientation (pointing upstream or downstream), sensor mounting angle, and flight height were parameters that required thorough testing. As sensor orientation, according to manufacturer recommendation and previous studies [31], upstream was preferred but downstream was also tested. As sensor mounting angle, values around $45^{\circ}$ were tested, because of the compromise between return signal strength and footprint size. Flight height required careful evaluation for the following considerations:

1. while the sensor can theoretically measure from up to $20-25 \mathrm{~m}$ altitude above the water surface, the signal strength decreases with altitude. Thus lower altitude is preferable for good SNR.

2. Lower altitude translates into a smaller footprint, which is a positive effect in terms of spatial resolution but a negative effect in terms of the size of the area in which measurements are averaged. In particular, smaller areas may also correspond to fewer scatterers, thus may even result in a weaker signal.

3. Furthermore, during flight at low altitude (less than $6-7 \mathrm{~m}$ above the water surface), the UAS-generated downwash induces significant turbulence on the water surface, thus affects the water surface velocity (undesired effect) whilst at the same time also increasing surface roughness (positive effect) [38].

Different tests were conducted to estimate the best flight height. From these tests, an optimal flight height of ca. 6 meters above the water surface was identified because, at this flight altitude, the water surface velocity was not affected by the UAS downwash, similarly to [47].

Post-processing of the SVR was performed in scripts written in MATLAB. Filtering of the observations was performed to include only the observations during which: i) UAS was stable (less than $0.1 \mathrm{~m} / \mathrm{s}$ of UAS velocity vector magnitude) for at least 20 seconds ii) SNR $>6 \mathrm{dBm}$, iii) flow direction was consistent (depending on if the sensor was looking upstream or downstream), iv) vibration index<2, v) standard deviation of PPK-processed GNSS observations $<0.02 \mathrm{~cm}$.

\subsubsection{Extraction of the surface velocity profile along the XS}

The velocity field obtained by the PIV observations was projected into the XS line (defined by the coordinates of the pole markers on the right and left streambanks). For doing that, the XS was discretized in small intervals (25- $\mathrm{cm}$ wide). A similar method was then applied for PIV and for SVR:

- For PIV: each velocity vector retrieved at a maximum orthogonal distance to the XS line of 5 meters (ROI length) was assigned to an interval of the XS line by nearest neighbor search. The magnitude of the velocity vector was computed. In case multiple vectors contained in the ROI length were assigned to the same interval, a median 
(and standard deviation) of the magnitude of those velocity vectors and a spatial standard deviation were computed.

- $\quad$ FOR SVR: velocity observations were filtered according to the maximum orthogonal distance from the XS line (only observations at a maximum distance of 5 meters were included). A median (and standard deviation) was computed to average the SVR observations obtained during the sampling period during which the UAS-borne SVR was hovering in that XS interval.

\section{Results}

In this section, we show the results of the SVR and PIV and compare them with ground-truth observations.

\subsection{Comparison plots}

Figure 3 shows the tests in Guden_Svostrupvej: PIV tends to underestimate the velocity (compared to the ADCP) in the middle of the XS. The PIV error may have been caused by the following factors:

- $\quad$ The camera tilt angle was not nadir (tilted of ca. $30^{\circ}$ ) for complying with UAS legislation, which constrains UAS flights in the proximity of public roads (i.e. the bridge): the tilted camera could have introduced an uncorrected distortion effect affecting the pixel into metric unit conversion.

- $\quad$ Seeding was not uniformly distributed and tended to cluster.

- Wind (ca. $0.7 \mathrm{~m} / \mathrm{s}$ ) flowing against the river flow may have affected the seeding speed.

- $\quad$ ADCP does not measure velocity at the water surface, but only $0.2 \mathrm{~cm}$ below it

The SVR seems to properly represent the velocity in the center part, but fails to measure velocity close to the edges. In particular, this occurs at the right edge, in which SVRmeasured velocity rapidly increases to unrealistic values (ca. $2 \mathrm{~m} / \mathrm{s}$ ), while ADCP velocity shows values around $0.7 \mathrm{~m} / \mathrm{s}$. The values of PGA around 20 for the entire flight duration (and the detected signal power) could not explain the anomaly: partly because of these results, the SVR manufacturer decided to develop a new firmware version to output SNR level. However, the manufacturer explained that the anomaly on the right edge may be an effect of the roughness of the water surface that becomes too low (as visible also on the video frames), causing unrealistic SVR velocities (too high). Indeed, according to manufacturer specifications, insufficient water roughness can generate unrealistic (either too high or too low) velocity estimations. 

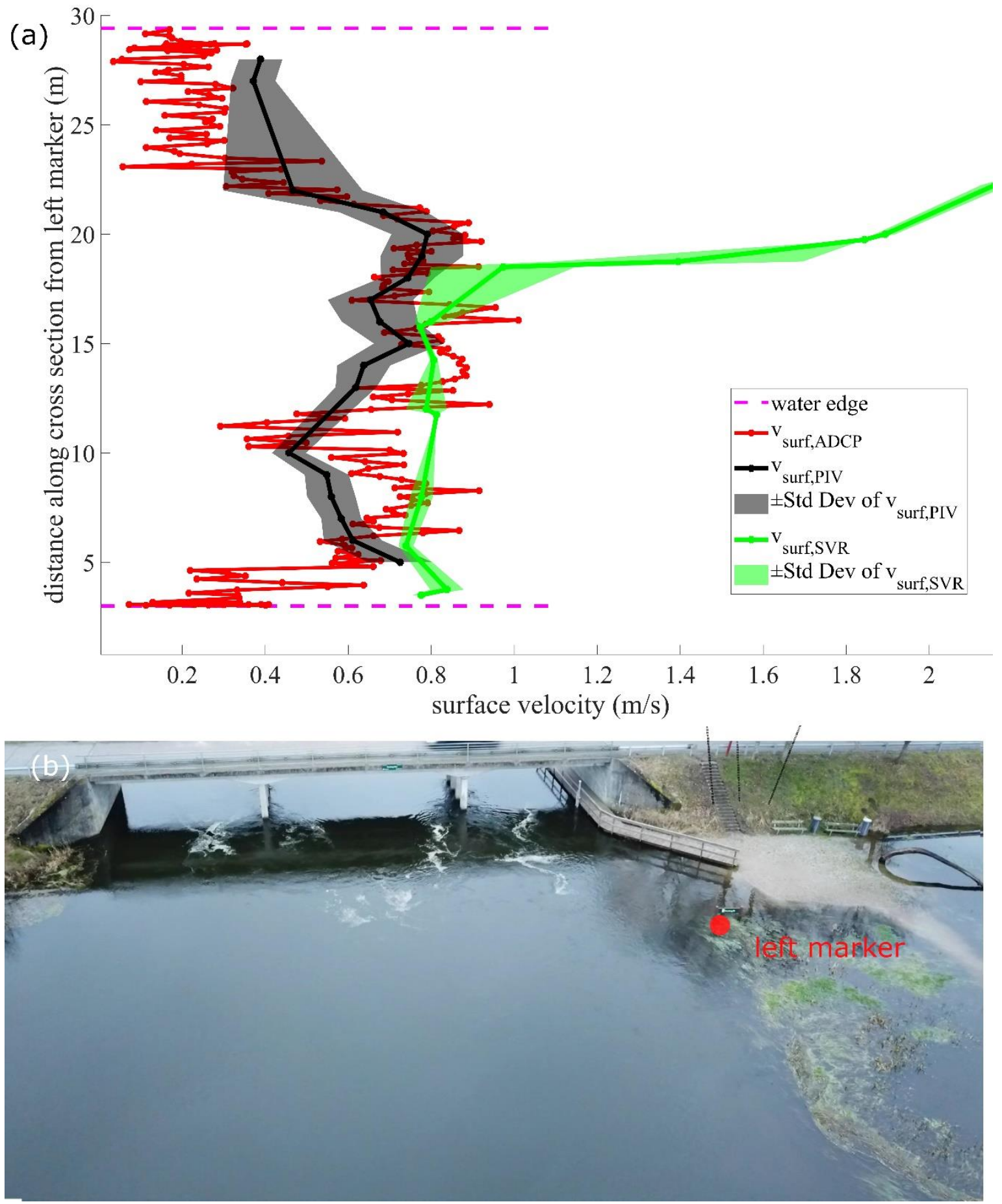

Figure 3, Guden_Svostrupvej XS. (a) surface velocity plot comparing: ADCP measurements of surface velocity (Vsurf,ADCP), UAS-borne PIV (Vsurf,PIV) and UAS-borne SVR (Vsurf,SVR). SVR and PIV are represented with shaded grey (PIV) and shaded green (SVR) to present standard deviation $( \pm$ Std Dev). (b) shows a UAS-borne video frame with also a red point indicating where the left marker was placed.

Figure 4 shows the UAS-borne PIV, static and UAS-borne SVR (with the updated firmware enabling SNR output) tests conducted in Guden_GamleSkibelundvej. The PIV shows a good correlation compared to the surface velocity measured with MFpro. On the right streambank, the standard deviation (Std Dev) is rather high, which is caused by the high spatial variability along the river course. Static tests were performed from the bridge by holding the SVR static; to obtain the velocity profile, the system was moved 
from one position to the other (at intervals of ca. 1 meter) across the XS (with the system standing for 2 minutes at each position). Figure 4 shows the static test results for both the tests in which SVR pointed upstream and downstream. Since the upstream and downstream tests were conducted from the two sides of the bridge, the actual water surface area measured by the SVR footprint was different between the two tests, thus surface velocity may slightly differ between the two cases. Both of these tests show a good agreement with MFpro. The test in which the SVR was pointed upstream shows better results (in terms of velocity comparison with ground-truth) than the downstream-looking test, especially in the center of the XS and on the left side. The advantage of pointing the SVR upstream is also shown by the SNR values (significantly higher in the upstream-looking test). The downstream-looking test gave SNR $<7$ on the right side of the XS (after ca. 20 meters distance from left marker), thus those observations are omitted (as described in the Materials and Methods chapter). In contrast, the upstream-looking test shows a very high SNR value (ca. 20) at 20 meters from the left marker and a sharp decline of SNR towards the right marker: however, the velocities detected in the upstream-looking test are inaccurate in that part of the XS.

After these two static tests, additional static tests were performed a few hours later but all of them showed significantly lower SNR and unrealistic velocity results: this may be an effect of decreased wind speed, which caused a reduced surface roughness. Tests with UAS-borne SVR also show very low SNR and unrealistic (too high) surface velocity measurements in most of the XS (apart from few points that gave realistic measurements). The UAS-borne test also shows a PGA value fluctuating between 5-10, which, surprisingly, is lower than for the static test. A lower PGA may suggest that the SVR is disturbed by the UAS instability and high-frequency vibrations and, also because of low water surface roughness, is unable to detect surface water speed. Thus UAS-borne SVR tests in Denmark were not successful and additional tests were conducted in Sweden, in rivers with higher surface roughness. 

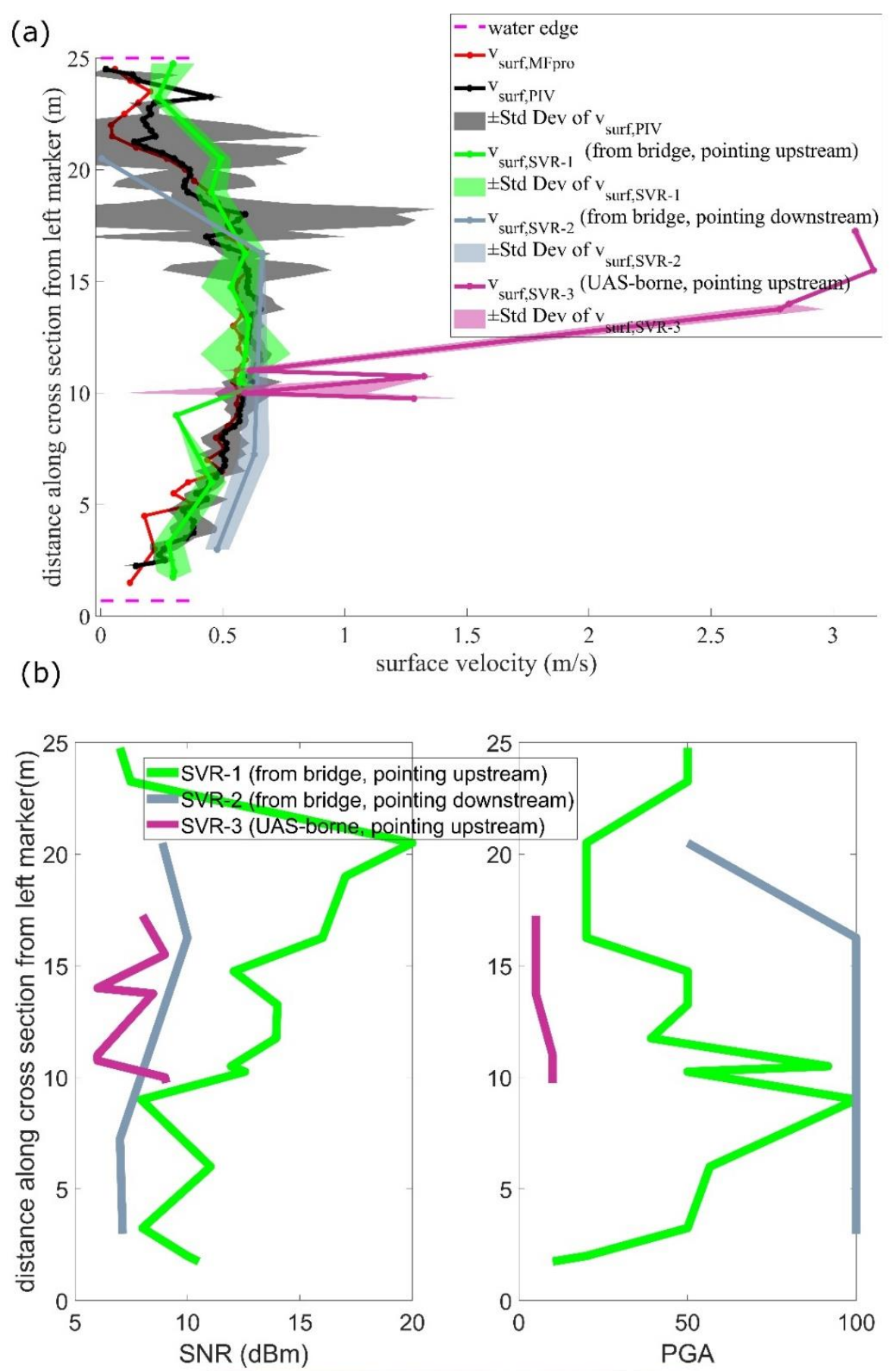

(c)

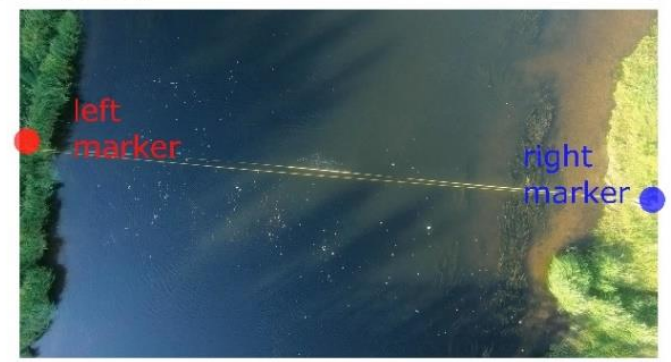

Figure 4, Guden_GamleSkibelundvej XS. (a) Surface velocity comparing: MFpro measurements of surface velocity (Vsurf,MFpro), UAS-borne PIV measurements (Vsurf,PIV) and three SVR surveys . Two SVR are retrieved from bridge, i.e. Vsurf,SVR1 (pointing upstream), Vsur,SVR2 (pointing downstream), whilst one from UAS, i.e. (Vsur,SVR3, pointing upstream). SVR and PIV are represented with shaded regions to present standard deviation $( \pm$ Std Dev). (b) Comparison of two quality indicators (SNR and PGA) for the three SVR surveys. (c) UAS-borne video frame of the XS 
Figure 5 shows the result for the Ätran river cross section. In this case, the river was several meters deep and fast flowing, thus no ground-truth was retrieved with MFpro and only UAS-borne PIV observations can be used as reference. The PIV shows a low velocity portion in the middle of the XS, where a submerged island is located and flow is thus significantly reduced. In this XS, three UAS-borne SVRs tests were conducted. UASborne SVR shows significantly higher SNR than in the UAS-borne tests in Denmark, as a consequence of the high surface roughness. The UAS-borne tests also show a very low PGA, which indicates a very strong signal, but PGA below 5 may also indicate SVR saturation and thus reduced accuracy. The first SVR test shows relatively good correspondence with PIV in the high velocity portion but poor matching with PIV in the area where the submerged island is. The second and third SVR surveys show erratic results, with a large mismatch compared to the first survey. Surprisingly, both the second and third SVR surveys show a low-velocity measurement around 11-12 meters from the left marker, in complete disagreement with PIV and the first SVR survey.

Figure 6 shows the test in Kilan. In this river, a small non-submerged island divides the stream into two braided channels. In this case, PIV shows a good agreement with the acquired MFpro throughout the XS. The first SVR flight shows good agreement with MFpro in the channel with high velocity (apart from one SVR outlier at around 8 meters from the left marker). The first SVR flight shows faulty readings when part of the SVR footprint lies on the island; indeed, soil or grass in the SVR footprint can introduce large error sources (e.g. grass fluctuation caused by wind). Furthermore, the first flight is also unable to retrieve observations in the right side of the river (because of lower surface roughness resulting in SNR $<7$ ). The second SVR flight shows significantly lower surface velocity (ca. 15\% less) than the first SVR flight in the left side of the river (higher flow portion) and also shows faulty readings in the portion where the island lies and on the right side of the river. Thus, the repeatability of UAS-borne SVR results is questionable.

The repeatability of UAS-borne SVR results is also poor in the XS in Krokån river, shown in Figure 7. Three SVR flights were conducted on this site. During the first flight, the SVR was pointed downstream and the SNR was the poorest among the three flights. The second flight (pointing upstream) gave the best results in terms of velocity comparison with MFpro, but velocity in the slow flow portions is overestimated with SVR. The third flight (pointing upstream) matches poorly with the second flight, even though SNR and PGA indicators are similar. Also in this XS, UAS-borne PIV matched well with MFpro. 


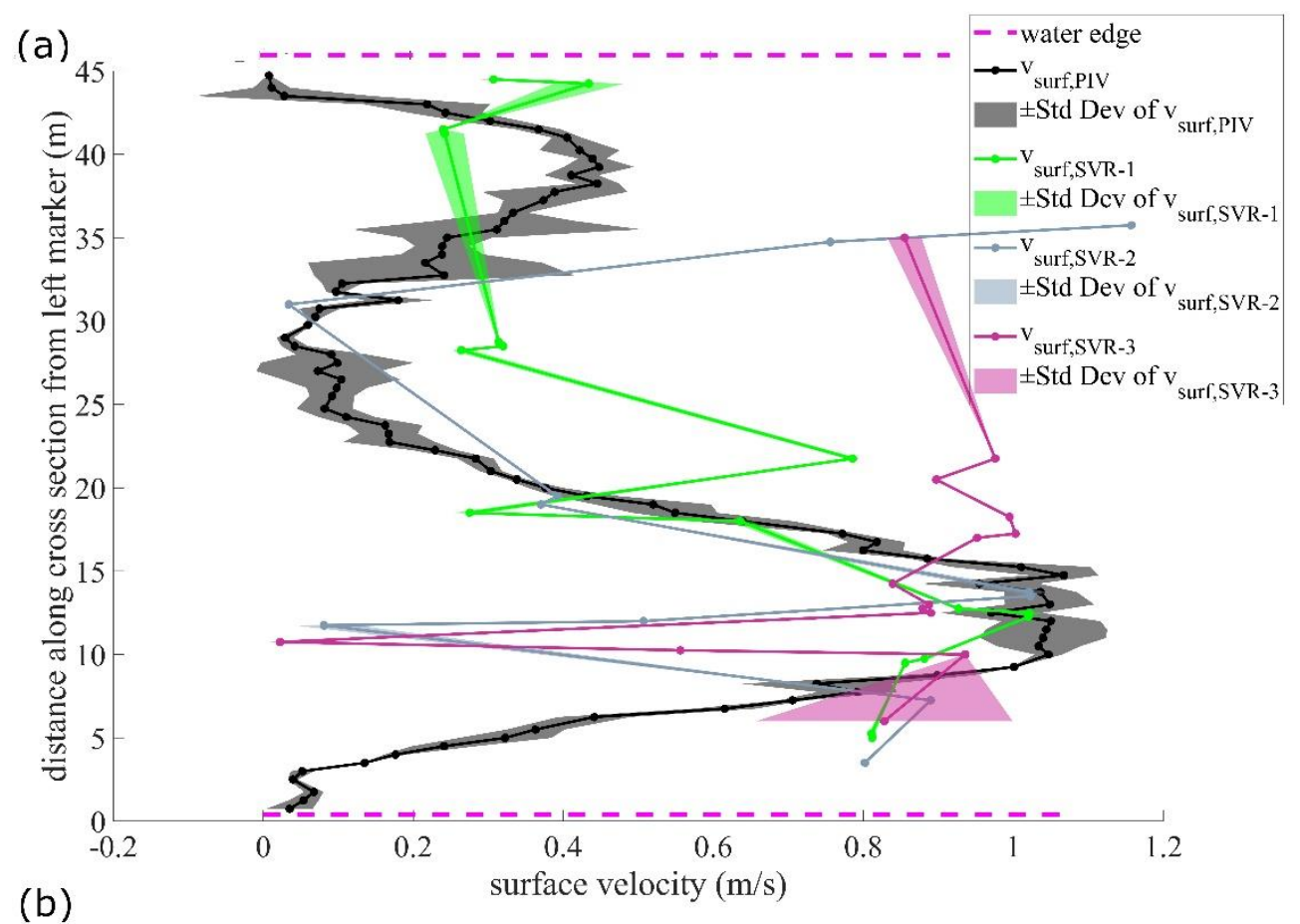

(b)

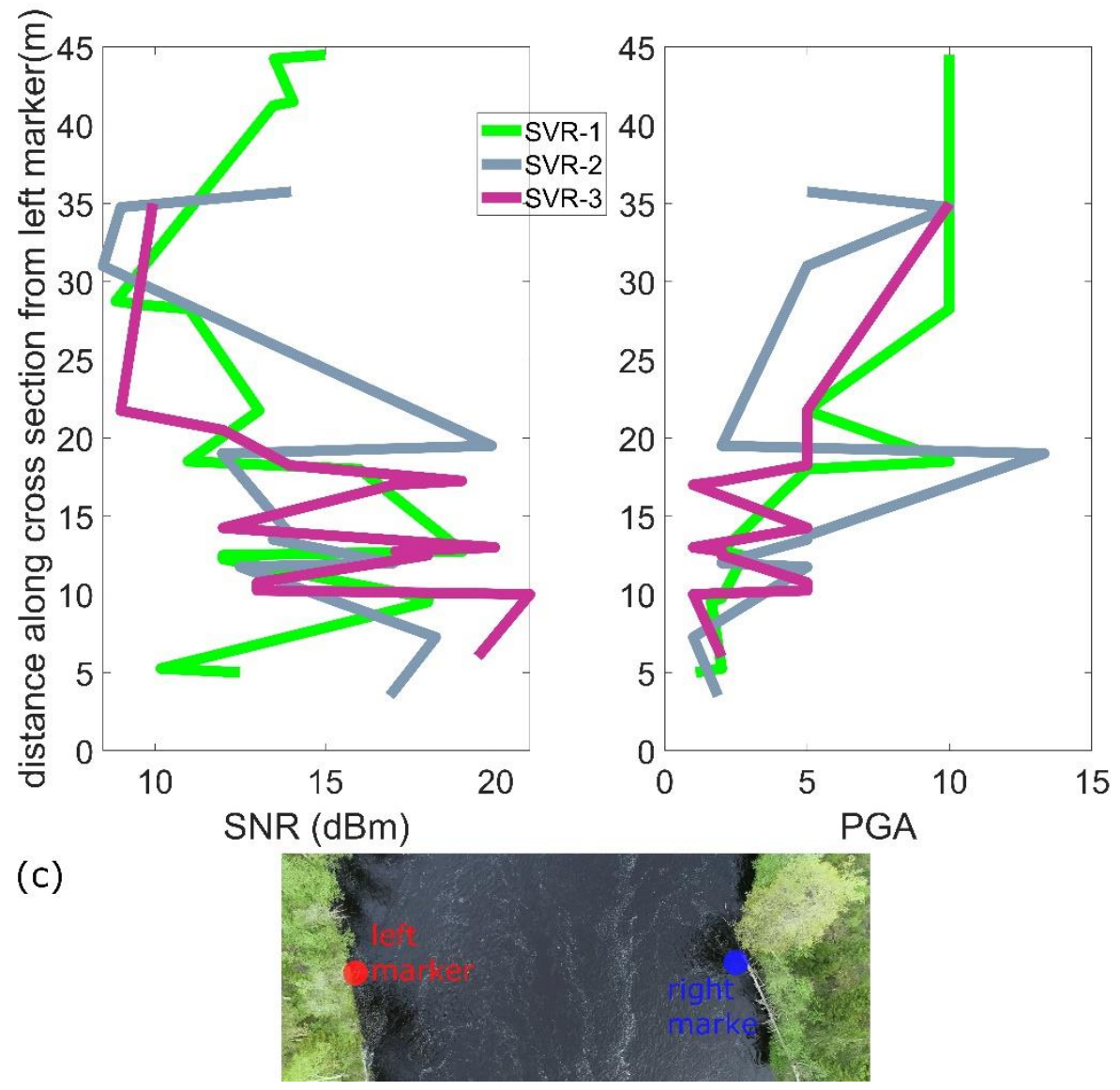

Figure 5, ̈̈tran XS. (a) surface velocity comparing: UAS-borne PIV measurements (Vsurf,PIV) and three UAS-borne SVR (Vsurf,SVR -1, Vsurf,SVR-2 and Vsurf,SVR-3, all of which pointing upstream) surveys. SVR and PIV are represented with shaded regions to present standard deviation ( \pm Std Dev). (b) Comparison of two quality indicators (SNR and PGA) for the SVR surveys. (c) UAS-borne video frame of the XS 
(a)

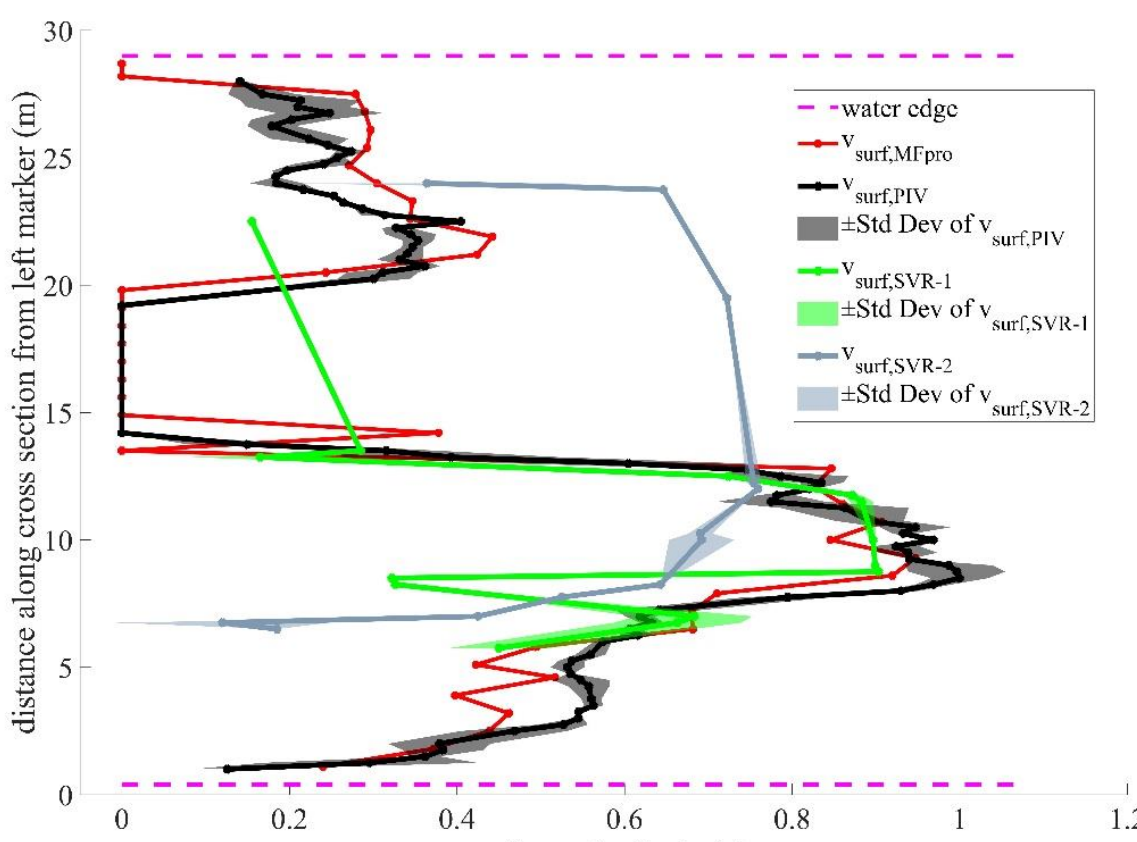

(b)
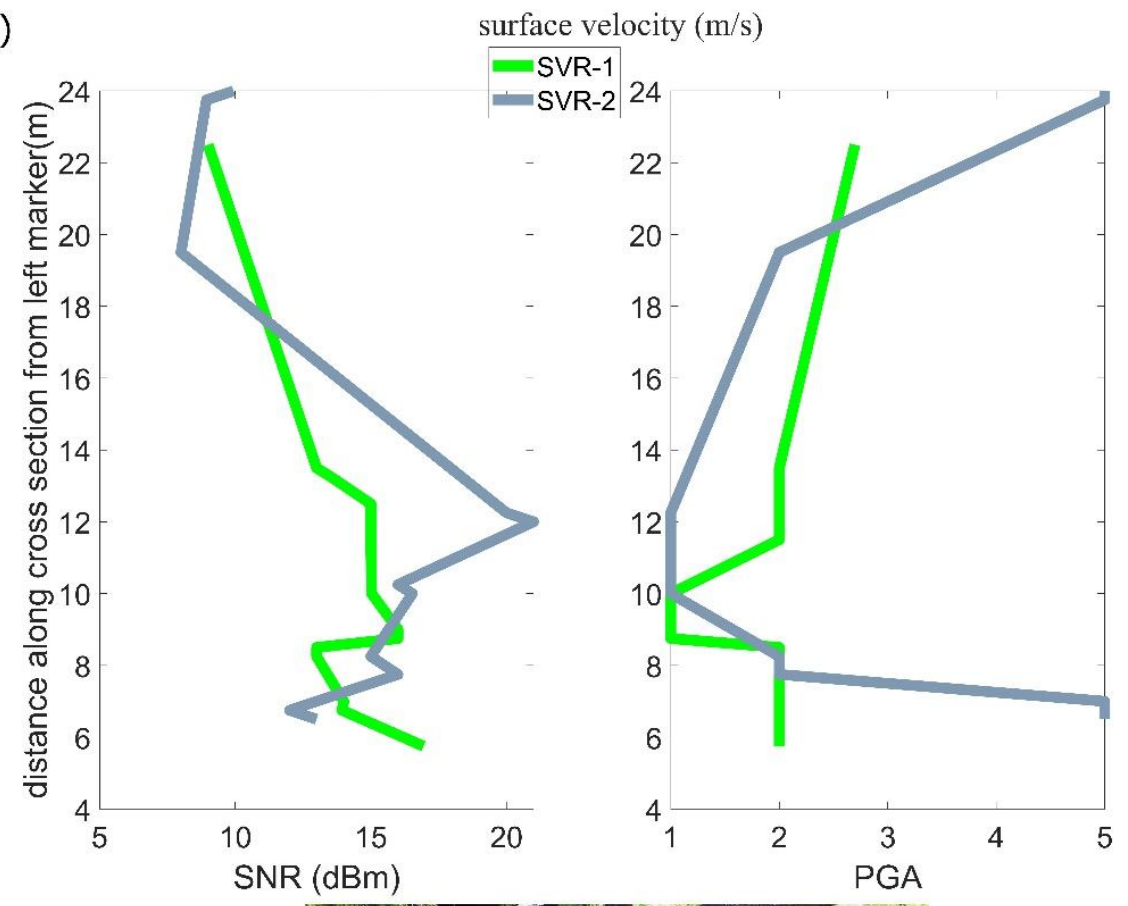

(c)

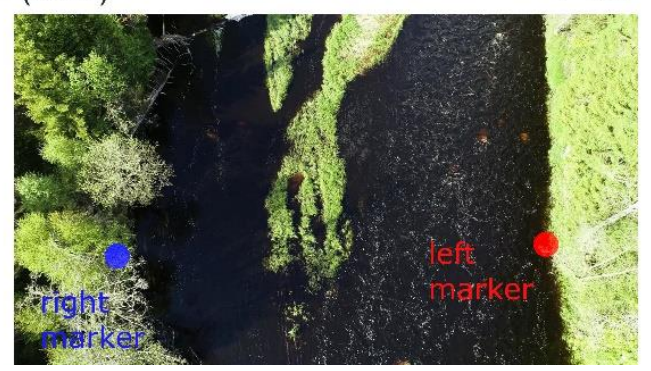

Figure 6, Kilan XS. (a) surface velocity comparing: MFpro measurements of surface velocity (Vsurf,MFpro), UAS-borne PIV measurements (Vsurf,PV) and two UAS-borne SVR (Vsurf,SVR-1, Vsurf,SVR-2, all of which pointing upstream) surveys. SVR and PIV are represented with shaded regions to present standard deviation ( \pm Std Dev). (b) Comparison of two quality indicators (SNR and PGA) for the SVR surveys. (c) UAS-borne video frame of the XS 
(a)

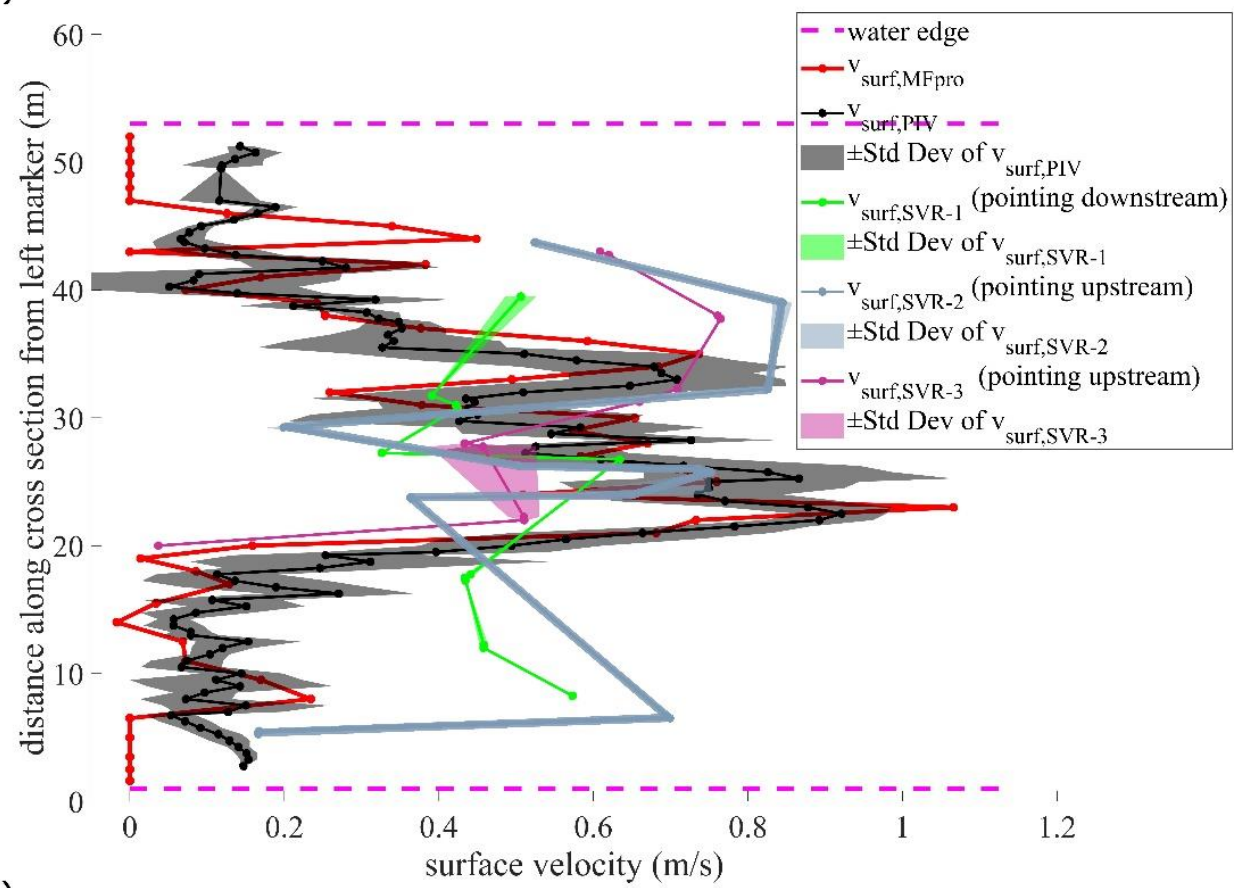

(b)
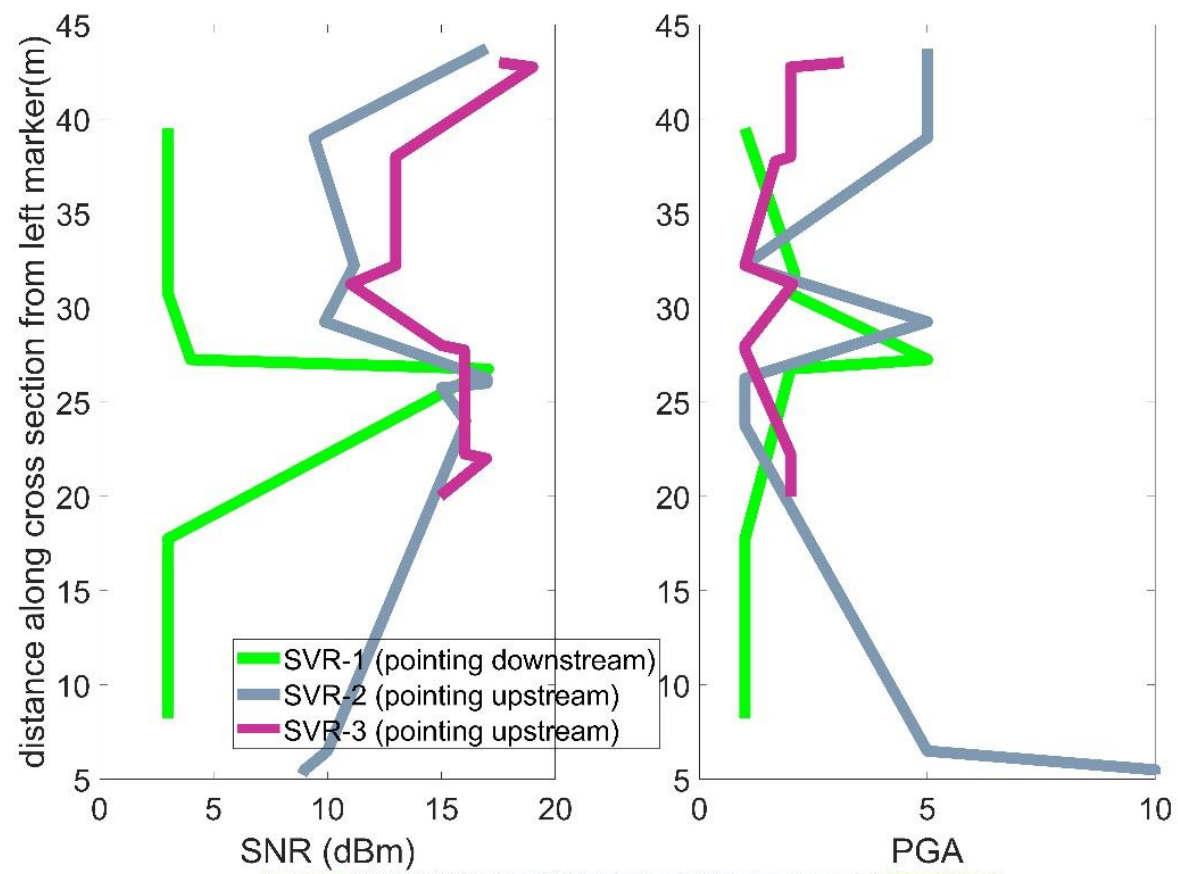

(c)

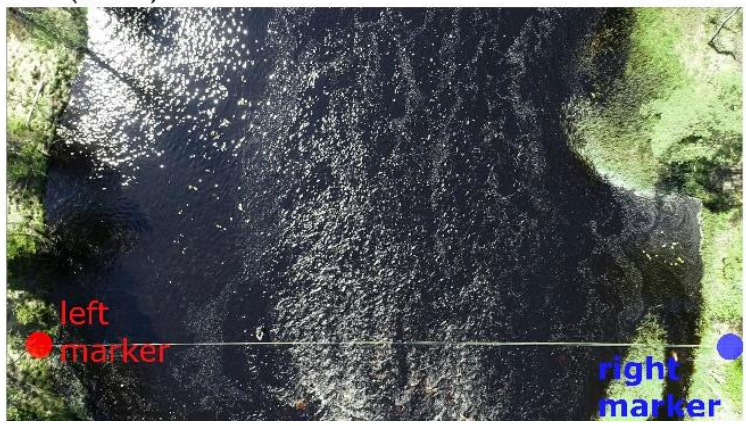

Figure 7, Krokån XS. (a) surface velocity comparing: MFpro measurements of surface velocity (Vsurf,MFpro), UAS-borne PIV measurements (Vsurf,PIV) and three UAS-borne SVR (Vsurf,SVR -1 pointing downstream, Vsurf,SVR-2 and Vsurf,SVR-3 pointing upstream) surveys. (b) Comparison of two quality indicators (SNR and PGA) for the SVR surveys. SVR and PIV are represented with shaded regions to present standard deviation ( \pm Std Dev). (c) UAS-borne video frame of the XS 


\subsection{Statistics}

The UAS-borne SVR showed poor repeatability between the surveys at the same XS and very large errors at low velocity, with land or vegetation in the SVR footprint (e.g. close to the streambanks, islands in the middle of the streams) or in the locations with low surface roughness, often resulting in unrealistic velocity measurements. Because of these problems, a statistical comparison of SVR velocimetry results and results from other methods is not meaningful. On the other hand, UAS-borne PIV showed good agreement with MFpro, thus statistics were computed.

Table 2 shows the Mean Absolute Error (MAE), Mean Bias Error (MBE) and Root Mean Square Error (RMSE) computed by comparing the surface velocity observations retrieved by PIV (interpolated at MFpro spatial resolution) with the observations retrieved with MFpro. Table 2 shows that errors in the order of a few $\mathrm{cm} / \mathrm{s}$, apart from the first XS in Guden_Svostrupvej in which errors of ca. $14 \mathrm{~cm} / \mathrm{s}$ occur.

Table 2, statistics comparing the surface velocity measurements retrieved with PIV and groundtruth (MFpro for all XS, apart from Guden_Svostrupvej where ADCP was used). MAE is Mean Absolute Error, MBE is Mean Bias Error, RMSE is Root Mean Square Error.

\begin{tabular}{cccc}
\hline & MAE & MBE & RMSE \\
\cline { 2 - 4 } Site Name & $(\mathbf{m} / \mathbf{s})$ & $\mathbf{( m / s )}$ & $(\mathbf{m} / \mathbf{s})$ \\
\hline Guden_Svostrupvej & 0.14 & -0.01 & 0.16 \\
\hline Guden_GamleSkibelundvej & 0.06 & 0.04 & 0.07 \\
\hline Ätran & - & - & - \\
\hline Kilan & 0.08 & -0.02 & 0.11 \\
\hline Krokån & 0.11 & -0.01 & 0.15 \\
\hline
\end{tabular}

\section{Discussion}

We discuss the results of the two techniques (PIV and SVR) and the advantages and disadvantages of both.

\subsection{PIV}

\subsubsection{PIV advantages}

PIV has several advantages compared to SVR, including:

1. PIV estimates both magnitude and angle of the velocity vector (thus can detect velocity along and across the XS).

2. PIV estimates the velocity field over the entire XS width in one single video and gives also information about the spatial variability along the portion of the river course that is visible in the video.

3. PIV estimates velocity with a high spatial resolution (typically dependent on the interrogation area size)

4. PIV videos can be stabilized so that the effects of drone vibrations and drifts are reduced.

\subsubsection{PIV limitations}

PIV has also some significant limitations:

1. Seeding characteristics, such as density and distribution, control the quality of PIV estimates $[21,24]$. Artificial seeding was used in the Danish streams, in which the number of trackable natural features on the water surface was insufficient. Thus, in those conditions, PIV required one operator for flying the UAS and multiple operators to add artificial seeding. This was not the case in Swedish streams, in which a sufficient number of natural particles or foam was present. However, if the streams 
were surveyed during different seasons, the foam (generated by decomposition processes) may be not visible, thus artificial seeding may be required.

2. PIV requires some processing time: ca. 20-30 minutes per survey when PIV is applied. Indeed, even though most post-processing can be automatized, time is still required for video editing, sequence selection, stabilization and PIVlab processing.

3. PIV is cumbersome in very large rivers: the surveyed rivers were only a few tens of meters wide (the widest XS was ca. 50 meters); however if the rivers were several tens or hundreds of meters, it would be impossible to cover the entire river width with a single video and thus multiple videos should be acquired, causing additional complexity in i) georeferencing every single video or/and mosaicking multiple videos ii) stabilizing videos in which stable features on streambanks are not visible iii) adding artificial uniform seeding over large river widths in cases where natural seeding is insufficient.

4. The velocity at which seeding moves is directly affected by wind. This is especially critical for lightweight tracers, which are more affected by wind because a large portion of their volume is above the water surface

\subsubsection{PIV results}

PIV velocimetry results agree very well with MFpro with errors of few $\mathrm{cm} / \mathrm{s}$, apart from one XS (Guden_Svostrupvej) in which surface velocity is underestimated with PIV in the center of the XS and overestimated on the right side of the XS, mainly due to camera tilt angle (distortion effect), poor seeding density, wind effects (and potentially also because ground-truth was acquired with ADCP instead of MFpro).

\subsubsection{Comparison of PIV results with previous studies}

The estimated PIV accuracy is in agreement with previous studies. For example, Dal Sasso et al. [52] found RMSE of 0.1-0.2 m/s (with large percentage error at low velocities) when comparing UAS-borne PIV estimates and velocity probe estimates. Strelnikova et al. [6] also found errors in UAS-borne PIV compared to ground truth in the order of few $\mathrm{cm} / \mathrm{s}$ or $\mathrm{dm} / \mathrm{s}$, with significantly higher percentage errors for low velocities.

De Schoutheete et al. [49] found that PIV significantly overestimates velocity compared to MFpro estimates (because MFpro has to be fully submerged in order to estimate velocity), with an average bias of ca. 0.86 that was introduced as a constant bias correction by the authors. Such a large bias was not found in our case, but in three out of four tests, PIV slightly underestimated velocity compared to MFpro. The black and white masking of the video frames, which was used to mask the seeding from the surroundings, allowed for focusing on portions where seeding was present. The developed masking method was especially useful in the XSs where no artificial seeding was added or with non-uniform seeding density, because it avoids averaging real measurements with false zero velocities and consequently underestimating velocity, as reported in $[3,6,24]$.

\section{2. $S V R$}

SVR has some important advantages compared to PIV, but also some major disadvantages.

\subsubsection{SVR advantages}

The main advantages of SVR compared to PIV are:

1. SVR does not require seeding on the water surface

2. SVR processing time is deterministic and can be fully automatized, making it suitable also for real-time velocity determination (e.g. during floods)

3. SVR is ideal to be applied in large rivers (e.g. several tens or hundreds of meters wide), especially when the SVR footprint is small compared to the river width. In this case, a flight conducted at 10-15 meters altitude across an XS could measure the entire horizontal velocity profile. 


\subsubsection{SVR limitations}

SVR also showed several limitations:

1. The SVR (and Doppler radar instruments in general) requires water roughness for receiving a sufficient amplitude of backscattered signal. This may be critical over lowland streams which have soft riverbed materials, mild slopes and velocities. In those rivers, the main source of surface roughness would be wind.

2. Microwave antennas of Doppler radar instruments have a beamwidth on the order of a few tens of degrees. The SVR footprint is large $\left(12^{\circ}\right.$ Azimuth, $24^{\circ}$ Elevation, e.g. at 6 meters altitude and $45^{\circ}$ tilt angle, the footprint would have a major axis of $5.3 \mathrm{~m}$ and a minor axis of $1.8 \mathrm{~m}$, with the center of the footprint located 6 meters away from the SVR horizontal position): only one averaged observations is output for the entire footprint. This leads to a poor spatial resolution and becomes critical when the velocity changes rapidly along the river width.

3. The SVR only measures the velocity of waves traveling toward or away from the antenna in the plane of incidence, thus cannot determine the velocity in all the other directions.

4. The SVR velocity measurements could not be corrected for drone vibrations and drifts. Since the UAS-borne Inertial Measurement Unit and GNSS system can measure UAS velocity, roll angle, pitch angle and heading, ideally the Doppler radar measurements should be corrected for these known drone movements. This would require the Doppler radar to output raw phase shift observations, preferably at high temporal resolution, but this is not possible with the SVR used in this study.

5. The tested SVR instrument has internal filters that are optimized for static deployment. Despite the choice of filter type (moving average or infinite impulse response) and filtering window, our tests show that the SVR needs a long time (at least 30 seconds) during which the SVR is stable before the velocity measurements are smoothed, as also reported by Fulton et al. [47]. This can become critical for UASdeployment, in which drone vibrations and drifts have a direct impact on measured velocity.

\subsubsection{SVR results}

The observations acquired with SVR static from a bridge (only tested in Guden_GamleSkibelundvej XS) showed a good match to the MFpro (especially for the case of SVR pointing upstream). However, the water roughness in that specific XS was at the minimum limit; indeed, static tests that were performed a couple of hours later, when wind speed was lower, resulted in too low SNR and unrealistic measurements.

The observations acquired with UAS-borne SVR in Danish rivers showed unrealistic velocity, apart from a portion of the test in Guden_Svostrupvej in which velocity measurements show a proper match with MFpro. The unrealistically high $(2 \mathrm{~m} / \mathrm{s})$ UAS-borne SVR measurements are not directly caused by the UAS velocity; indeed, measurements are acquired by flying the UAS to the hovering position at low speed (ca. $0.5 \mathrm{~m} / \mathrm{s}$ ) and then make it hover for at least 30 seconds (only observations retrieved after 20 seconds hovering are accepted). However, the UAS vibration and drift can affect SVR internal processing, including the PGA settings, especially when the water roughness (and thus the SNR) is marginal. The observations retrieved in Swedish rivers with UAS-borne SVR show significantly higher SNR and lower PGA (especially in the high velocity portions). However, despite a few SVR flights showing a good match with MFpro in the high flow portions, the repeatability of SVR measurements retrieved during different SVR flights is poor. In general, we suggest that the main error sources are related to:

1. The uncertainty in UAS navigation (typically a couple of meters) and in UAS height (ca. 0.5 meters), together with the large SVR scanning angle, that may cause that the water surface areas illuminated by the SVR antennas are different.

2. The uncertainty in UAS heading angle $\left(\mathrm{ca} .5^{\circ}\right)$ that may cause misalignment between the UAS-borne SVR and the flow direction of the river. 
3. Disturbance caused by the SVR antenna beam illuminating portions of soil or vegetation, as also reported in Fulton et al. [47]. This was the case for the test conducted in Kilan river, which showed that the island in the middle caused unrealistic velocity readings, and in all the measurements conducted close to the streambanks.

4. Errors caused by multipath, e.g. radiation hitting the UAS and further reflected towards water, should be further examined because they can be substantial as the UAS is made of conductive carbon fiber.

5. The sites in Denmark showed too low water roughness (low SNR). However, in the Swedish tests, PGA is typically less than 5, which, according to the manufacturer, may mean that the reflected signal is very strong, and the receiver may be oversaturated, which could result in reduced accuracy. Thus, selection of sites should be done carefully as high water roughness (e.g. strong macro-turbulence) can limit the accuracy, whilst too low water roughness results in unreliable measurements. Ideally, according to Melcher et al. [38], water roughness should be preferably caused by wind.

\subsubsection{Wind effect and flight altitude}

High wind speed has a positive effect on water roughness; however, it affects drone stability, which may cause large inaccuracies in UAS-borne SVR readings and, in addition, wind affects water surface velocity. The magnitude of wind effect on surface velocity measurements performed by a Doppler radar was evaluated by Plant et al. [31], taking into account the effective depth at which water velocity is measured by microwave measurements. According to Plant et al. [31], the magnitude of the wind drift in the wind direction at the surface is ca. $2 \%$ of the wind speed measured at $10 \mathrm{~m}$ altitude. For a $10 \mathrm{~m} / \mathrm{s}$ wind speed, this corresponds to $20 \mathrm{~cm} / \mathrm{s}$, thus not negligible. When there was not wind to increase surface roughness, Melcher et al. [38] flew the manned helicopter at a lower altitude and used the propeller-generated downwash to increase the water surface roughness. However, in that research the authors could deploy two antennas, one on each side of the helicopter, to remove the water velocity components caused by the propeller downwash from the actual flow velocity (indeed downwash-generated waves always move away from the helicopter). Deployment of two antennas on both sides of the UAS was not possible here, thus the water velocity effect caused by low UAS flights could have directly affected SVR readings. Furthermore, the downwash generated by a UAS is significant but does not have the same intensity and distance of influence as for a manned helicopter. A few tests (not shown in this paper) were performed in Guden_GamleSkibelundvej XS at altitude as low as 1.5 meters above the water surface; however, the SNR reported during those UAS-borne flights was not significantly higher than in the flights at an altitude of 6 meters and the velocity measurements were also unrealistic.

\subsubsection{Comparison of SVR results with previous studies}

Comparison can be made with helicopter deployment [38] and UAS-borne deployment [47]. Melcher et al. [38] found good agreement between helicopter-borne Doppler radar and ground-truth, typically in the order of a few decimeters/s. However, the measured velocities were significantly higher (up to $2.5 \mathrm{~m} / \mathrm{s}$ ) and the river was wider (ca. 100 meters) than at our sites, thus we may expect that faster flow and the wider river geometry conditions were more favorable. Fulton et al. [47] found an excellent correlation between velocity measured with a UAS-borne Doppler radar and velocity measured with a handheld velocity radar and an acoustic Doppler velocimeter; however, only the maximum cross-section surface velocity was reported with UAS-borne SVR and the surface roughness of the sites was unknown.

\subsection{Future research}

For PIV, we suggest that future research should be conducted to make the seeding process more autonomous, for example by using a secondary UAS.

For SVR, more tests should be conducted in streams with different surface roughness conditions, especially in situations in which surface roughness is mainly caused by wind. Furthermore, UAS choice is critical, because the platform has to be very stable also in 
windy conditions. Additionally, flight missions should be performed in fully automatic flight mode with RTK GNSS, to ensure centimetric accuracy in navigation and at least 1$2^{\circ}$ heading accuracy. The error caused by multi-path (e.g. from UAS structure) should be further evaluated. Moreover, a Doppler radar that can output raw Doppler shift information should be preferred to customize post-processing for UAS deployment (e.g. to correct for drone vibrations).

\title{
5. Conclusions
}

A commercial $24 \mathrm{GHz}$ Doppler radar, developed for static deployment, was readapted for UAS-borne use for estimating the horizontal velocity profile across river crosssections. Furthermore, the velocity profile was also estimated with UAS-borne PIV.

Different tests were conducted in two Danish XSs (Guden A stream), characterized by mild slopes, soft riverbed material and low water roughness, and in three Swedish rivers, characterized by relatively steep slopes, hard riverbed material and high water roughness. We compared PIV and SVR measurements and benchmarked them against ground-truth acquired with an electromagnetic velocity probe (MFpro) or with ADCP:

- $\quad$ The static SVR test (from bridge) conducted in Guden $\AA$ showed good agreement with ground-truth velocity measurements (apart from the portion close to the streambanks)

- The UAS-borne SVR tests conducted in Guden Å showed unrealistic velocity observations, apart from a portion of the one XS (Guden_Svostrupvej), which showed good agreement with ground-truth.

- $\quad$ The UAS-borne SVR conducted in Sweden showed high SNR and in some cases good agreement with ground-truth in the faster flowing portions. However, different SVR flights showed significant differences in SVR measurements, thus the repeatability of the results should be further investigated.

- $\quad$ PIV matched well with ground-truth in the Swedish rivers (where natural seeding was sufficient) and in Denmark (where artificial seeding was added) with typical velocity errors of $10 \mathrm{~cm} / \mathrm{s}$ or better. Only in one XS, the errors were larger because of wind, clustering seeding, non-nadir looking camera (and potentially because in that case, ground-truth was acquired with ADCP, which can measure velocity only ca. 0.2 $\mathrm{m}$ below the surface).

\begin{abstract}
Author Contributions: Conceptualization, F.B. and P.B.; methodology, F.B., M.C.F., J.L., K.S., S.K. and P.B.; software, F.B., K.S. and S.K.; validation, F.B. and P.B; writing-original draft preparation, F.B.; writing - review and editing, F.B., M.C.F., J.L., K.S., S.K. and P.B.; funding acquisition, F.B. and P.B. All authors have read and agreed to the published version of the manuscript.
\end{abstract}

Funding: This work was supported by the projects RIVERSCAPES (file number 7048-00001B) and CHINAWATERSENSE (file number 8087-00002B) funded by the Innovation Fund Denmark (Innovationsfonden).

Data Availability Statement: The acquired data are available online in the repository archived in Zenodo.org (https://doi.org/10.5281/zenodo.5149856). The repository contains the videos used for the PIV velocimetry, the PIV results, the processed SVR data and the MFpro measurements.

Acknowledgments: We thank Stefan Siedschlag from OTT HydroMet (Germany) for lending the OTT SVR100 and for all the provided instrument support.

Conflicts of Interest: The funders had no role in the design of the study; in the collection, analyses, or interpretation of data; in the writing of the manuscript, or in the decision to publish the results.

\section{References}

1. Sukhodolov, A.; Uijttewaal, W.S.J.; Engelhardt, C. On the correspondence between morphological and hydrodynamical 
patterns of groyne fields. Earth Surf. Process. Landforms 2002, doi:10.1002/esp.319.

2. Ashworth, P.J. Mid-channel bar growth and its relationship to local flow strength and direction. Earth Surf. Process. Landforms 1996, doi:10.1002/(SICI)1096-9837(199602)21:2<103::AID-ESP569>3.0.CO;2-O.

3. Jodeau, M.; Hauet, A.; Paquier, A.; Le Coz, J.; Dramais, G. Application and evaluation of LS-PIV technique for the monitoring of river surface velocities in high flow conditions. Flow Meas. Instrum. 2008, 19, 117-127, doi:10.1016/j.flowmeasinst.2007.11.004.

4. Sayeed-Bin-Asad, S.M.; Lundström, T.S.; Andersson, A.G.; Hellström, J.G.I. A Review of Particle Image Velocimetry for Fish Migration. World J. Mech. 2016, doi:10.4236/wjm.2016.64011.

5. Strelnikova, D.; Paulus, G.; Käfer, S.; Anders, K.H.; Mayr, P.; Mader, H.; Scherling, U.; Schneeberger, R. Drone-based optical detection of heterogeneous surface flow patterns in the vicinity of fish ladders. Agit. J. fur Angew. Geoinformatik 2020, doi:10.14627/537698019.

6. Strelnikova, D.; Paulus, G.; Käfer, S.; Anders, K.H.; Mayr, P.; Mader, H.; Scherling, U.; Schneeberger, R. Drone-based optical measurements of heterogeneous surface velocity fields around fish passages at hydropower dams. Remote Sens. 2020, doi:10.3390/rs12030384.

7. Bandini, F.; Lüthi, B.; Peña-Haro, S.; Borst, C.; Liu, J.; Karagkiolidou, S.; Hu, X.; Lemaire, G.G.; Bjerg, P.L.; Bauer-Gottwein, P. A drone-borne method to jointly estimate discharge and Manning's roughness of natural streams. Water Resour. Res. 2020, doi:10.1029/2020wr028266.

8. Genç, O.; Ardiçlioğlu, M.; Ağiralioğlu, N. Calculation of mean velocity and discharge using water surface velocity in small streams. Flow Meas. Instrum. 2015, doi:10.1016/j.flowmeasinst.2014.10.013.

9. Bechle, A.J.; Wu, C.H. An entropy-based surface velocity method for estuarine discharge measurement. Water Resour. Res. 2014, doi:10.1002/2014WR015353.

10. Moramarco, T.; Corato, G.; Melone, F.; Singh, V.P. An entropy-based method for determining the flow depth distribution in natural channels. J. Hydrol. 2013, 497, 176-188, doi:10.1016/j.jhydrol.2013.06.002.

11. Legleiter, C.J.; Kinzel, P.J.; Nelson, J.M. Remote measurement of river discharge using thermal particle image velocimetry (PIV) and various sources of bathymetric information. J. Hydrol. 2017, doi:10.1016/j.jhydrol.2017.09.004.

12. Hauet, A.; Kruger, A.; Krajewski, W.F.; Bradley, A.; Muste, M.; Creutin, J.D.; Wilson, M. Experimental system for real-time discharge estimation using an image-based method. J. Hydrol. Eng. 2008, doi:10.1061/(ASCE)1084-0699(2008)13:2(105).

13. Patalano, A.; García, C.M.; Rodríguez, A. Rectification of Image Velocity Results (RIVeR): A simple and user-friendly toolbox for large scale water surface Particle Image Velocimetry (PIV) and Particle Tracking Velocimetry (PTV). Comput. Geosci. 2017, doi:10.1016/j.cageo.2017.07.009.

14. Thumser, P.; Haas, C.; Tuhtan, J.A.; Fuentes-Pérez, J.F.; Toming, G. RAPTOR-UAV: Real-time particle tracking in rivers using an unmanned aerial vehicle. In Proceedings of the Earth Surface Processes and Landforms; 2017.

15. Koutalakis, P.; Tzoraki, O.; Zaimes, G. Uavs for hydrologic scopes: Application of a low-cost UAV to estimate surface water velocity by using three different image-based methods. Drones 2019, doi:10.3390/drones3010014.

16. Tauro, F.; Piscopia, R.; Grimaldi, S. PTV-Stream: A simplified particle tracking velocimetry framework for stream surface flow monitoring. Catena 2019, doi:10.1016/j.catena.2018.09.009.

17. Tauro, F.; Piscopia, R.; Grimaldi, S. Streamflow Observations From Cameras: Large-Scale Particle Image Velocimetry or Particle Tracking Velocimetry? Water Resour. Res. 2017, doi:10.1002/2017WR020848.

18. Pearce, S.; Ljubicic, R.; Peña-Haro, S.; Perks, M.; Tauro, F.; Pizarro, A.; Dal Sasso, S.F.; Strelnikova, D.; Grimaldi, S.; Maddock, I.; et al. An evaluation of image velocimetry techniques under low flow conditions and high seeding densities using unmanned aerial systems. Remote Sens. 2020, doi:10.3390/rs12020232.

19. Perks, M.T.; Fortunato Dal Sasso, S.; Hauet, A.; Jamieson, E.; Le Coz, J.; Pearce, S.; Peña-Haro, S.; Pizarro, A.; Strelnikova, D.; Tauro, F.; et al. Towards harmonisation of image velocimetry techniques for river surface velocity observations. Earth Syst. Sci. Data 2020, doi:10.5194/essd-12-1545-2020. 
20. Lloyd, P.M.; Stansby, P.K.; Ball, D.J. Unsteady surface-velocity field measurement using particle tracking velocimetry. J. Hydraul. Res. 1995, doi:10.1080/00221689509498658.

21. Dal Sasso, S.F.; Pizarro, A.; Samela, C.; Mita, L.; Manfreda, S. Exploring the optimal experimental setup for surface flow velocity measurements using PTV. Environ. Monit. Assess. 2018, doi:10.1007/s10661-018-6848-3.

22. Eltner, A.; Sardemann, H.; Grundmann, J. Flow velocity and discharge measurement in rivers using terrestrial and UAV imagery. Hydrol. Earth Syst. Sci. Discuss. 2019, doi:10.5194/hess-2019-289.

23. Eltner, A.; Sardemann, H.; Grundmann, J. Technical Note: Flow velocity and discharge measurement in rivers using terrestrial and unmanned-aerial-vehicle imagery. Hydrol. Earth Syst. Sci. 2020, doi:10.5194/hess-24-1429-2020.

24. Pizarro, A.; Dal Sasso, S.F.; Perks, M.T.; Manfreda, S. Identifying the optimal spatial distribution of tracers for optical sensing of stream surface flow. Hydrol. Earth Syst. Sci. 2020, doi:10.5194/hess-24-5173-2020.

25. Dal Sasso, S.F.; Pizarro, A.; Pearce, S.; Maddock, I.; Manfreda, S. Increasing LSPIV performances by exploiting the seeding distribution index at different spatial scales. J. Hydrol. 2021, doi:10.1016/j.jhydrol.2021.126438.

26. Adrian, R.J. Twenty years of particle image velocimetry. In Proceedings of the Experiments in Fluids; 2005.

27. Tauro, F. Particle tracers and image analysis for surface flow observations. Wiley Interdiscip. Rev. Water 2016.

28. Tauro, F.; Petroselli, A.; Arcangeletti, E. Assessment of drone-based surface flow observations. Hydrol. Process. 2015, 30, 11141130, doi:10.1002/hyp.10698.

29. Tauro, F.; Porfiri, M.; Grimaldi, S. Surface flow measurements from drones. J. Hydrol. 2016, 540, 240-245, doi:10.1016/j.jhydrol.2016.06.012.

30. Detert, M.; Weitbrecht, V. A low-cost airborne velocimetry system: proof of concept. J. Hydraul. Res. 2015, 53, 532-539, doi:10.1080/00221686.2015.1054322.

31. Plant, W.J.; Keller, W.C.; Hayes, K. Measurement of river surface currents with coherent microwave systems. IEEE Trans. Geosci. Remote Sens. 2005, 43, 1242-1257, doi:10.1109/TGRS.2005.845641.

32. Plant, W.J.; Keller, W.C. Evidence of Bragg scattering in microwave Doppler spectra of sea return. J. Geophys. Res. 1990, doi:10.1029/jc095ic09p16299.

33. Wright, J.W. A New Model for Sea Clutter. IEEE Trans. Antennas Propag. 1968, doi:10.1109/TAP.1968.1139147.

34. Bass, F.G.; Fuks, I.M.; Kalmykov, A.I.; Ostrovsky, I.E.; Rosenberg, A.D. Very High Frequency Radiowave Scattering by a Disturbed Sea Surface Part II: Scattering from an actual sea surface. IEEE Trans. Antennas Propag. 1968, doi:10.1109/TAP.1968.1139244.

35. Yurovsky, Y.Y.; Kudryavtsev, V.N.; Grodsky, S.A.; Chapron, B. Sea surface Ka-band Doppler measurements: Analysis and model development. Remote Sens. 2019, doi:10.3390/RS11070839.

36. Plant, W.J. A model for microwave Doppler sea return at high incidence angles: Bragg scattering from bound, Tilted waves. J. Geophys. Res. Ocean. 1997, doi:10.1029/97JC01225.

37. Plant, W.J. Microwave sea return at moderate to high incidence angles. Waves Random Media 2003, doi:10.1088/0959$7174 / 13 / 4 / 009$.

38. Melcher, N.B.; Costa, J.E.; Haeni, F.P.; Cheng, R.T.; Thurman, E.M.; Buursink, M.; Spicer, K.R.; Hayes, E.; Plant, W.J.; Keller, W.C.; et al. River discharge measurements by using helicopter-mounted radar. Geophys. Res. Lett. 2002, doi:10.1029/2002g1015525.

39. Biondi, F.; Addabbo, P.; Clemente, C.; Orlando, D. Measurements of surface river doppler velocities with along-track InSAR using a single antenna. IEEE J. Sel. Top. Appl. Earth Obs. Remote Sens. 2020, doi:10.1109/JSTARS.2020.2976529.

40. Rosen, P.A.; Hensley, S.; Wheeler, K.; Sadowy, G.; Miller, T.; Shaffer, S.; Muellerschoen, R.; Jones, C.; Zebker, H.; Madsen, S. Uavsar: A new NASA airborne SAR system for science and technology research. In Proceedings of the IEEE National Radar Conference - Proceedings; 2006.

41. Fulton, J.; Ostrowski, J. Measuring real-time streamflow using emerging technologies: Radar, hydroacoustics, and the probability concept. J. Hydrol. 2008, doi:10.1016/j.jhydrol.2008.03.028. 
42. Lin, Y.S.; Chiu, S.F.; Chang, C.H. A $24 \mathrm{GHz}$ hydrology radar system capable of wide-range surface velocity detection for water resource management applications. Microw. Opt. Technol. Lett. 2020, doi:10.1002/mop.32479.

43. Welber, M.; Le Coz, J.; Laronne, J.B.; Zolezzi, G.; Zamler, D.; Dramais, G.; Hauet, A.; Salvaro, M. Field assessment of noncontact stream gauging using portable surface velocity radars (SVR). Water Resour. Res. 2016, doi:10.1002/2015WR017906.

44. Fulton, J.W.; Mason, C.A.; Eggleston, J.R.; Nicotra, M.J.; Chiu, C.L.; Henneberg, M.F.; Best, H.R.; Cederberg, J.R.; Holnbeck, S.R.; Lotspeich, R.R.; et al. Near-field remote sensing of surface velocity and river discharge using radars and the probability concept at 10 U.S. geological survey streamgages. Remote Sens. 2020, doi:10.3390/RS12081296.

45. Bolognesi, M.; Farina, G.; Alvisi, S.; Franchini, M.; Pellegrinelli, A.; Russo, P. Measurement of surface velocity in open channels using a lightweight remotely piloted aircraft system. Geomatics, Nat. Hazards risk 2016, 5705, doi:10.1080/19475705.2016.1184717.

46. Alimenti, F.; Bonafoni, S.; Gallo, E.; Palazzi, V.; Vincenti Gatti, R.; Mezzanotte, P.; Roselli, L.; Zito, D.; Barbetta, S.; Corradini, C.; et al. Noncontact measurement of river surface velocity and discharge estimation with a low-cost doppler radar sensor. IEEE Trans. Geosci. Remote Sens. 2020, 58, 5195-5207, doi:10.1109/TGRS.2020.2974185.

47. Fulton, J.W.; Anderson, I.E.; Chiu, C.L.; Sommer, W.; Adams, J.D.; Moramarco, T.; Bjerklie, D.M.; Fulford, J.M.; Sloan, J.L.; Best, H.R.; et al. QCam: SUAS-based doppler radar for measuring river discharge. Remote Sens. 2020, doi:10.3390/rs12203317.

48. Bandini, F.; Sunding, T.P.; Linde, J.; Smith, O.; Jensen, I.K.; Köppl, C.J.; Butts, M.; Bauer-Gottwein, P. Unmanned Aerial System (UAS) observations of water surface elevation in a small stream: Comparison of radar altimetry, LIDAR and photogrammetry techniques. Remote Sens. Environ. 2020, doi:10.1016/j.rse.2019.111487.

49. De Schoutheete, F.; D’odeigne, O. carlier; Soares-Frazão, S. Drone-Driven Surface Velocity Measurements in Natural Rivers Available online: https://www.iahr.org/paper/detail?paper_id=2928 (accessed on Jul 14, 2020).

50. Takasu, T.; Yasuda, A. Development of the low-cost RTK-GPS receiver with an open source program package RTKLIB. Int. Symp. GPS/GNSS 2009.

51. Thielicke, W.; Stamhuis, E.J. PIVlab - Towards User-friendly, Affordable and Accurate Digital Particle Image Velocimetry in MATLAB. J. Open Res. Softw. 2014, doi:10.5334/jors.bl.

52. Dal Sasso, S.F.; Pizarro, A.; Manfreda, S. Metrics for the quantification of seeding characteristics to enhance image velocimetry performance in rivers. Remote Sens. 2020, doi:10.3390/rs12111789. 